https://www.journal-imab-bg.org

Original article

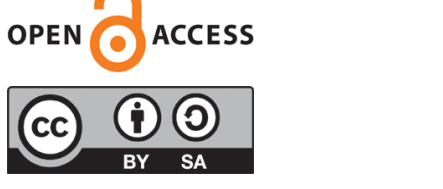

\title{
CONVENTIONAL VS DIGITAL IMPRESSION TECHNIQUE FOR MANUFACTURING OF THREE- UNIT ZIRCONIA BRIDGES: CLINICAL TIME EFFICIENCY
}

\author{
Kiril Gogushev, Metodi Abadjiev \\ Department of Clinics of Prosthetic Dental Medicine, Faculty of Dental \\ Medicine, Medical University - Varna, Bulgaria.
}

\begin{abstract}
:
Introduction: Taking an impression of the oral cavity, which accurately recreates the prosthetic field, the surrounding hard dental and soft tissues, is one of the main and most important stages in the process of making any fixed prosthetic restoration. In modern prosthetic dentistry, impressions taken with the help of polyether and vinyl polysiloxane impression materials are common. Digital impressions eliminate some of the steps of conventional impression techniques and save clinical time.

Aim: The aim of this article is to compare the clinical time in digital and conventional impression techniques from a whole dental arch using a controlled clinical trial.

Material and methods: The present study includes 36 patients from Varna who need prosthetic treatment with fixed 3-unit bridge construction. For all participants, the conventional impression technique was performed first and one week later - the digital one. All clinical manipulations related to the implementation of the two impression techniques were performed according to the instructions of the manufacturing companies by the same specialist dentist.

Results: In all participants, the time required to perform the digital impression technique is significantly less than that of the conventional impression technique.

Conclusion: The digital impression technique has proven to be more efficient in terms of clinical time required for its implementation than the conventional impression technique.
\end{abstract}

Keywords: digital, conventional, impression, time, clinical study, efficiency

\section{INTRODUCTION:}

Taking an impression of the oral cavity, which accurately reproduces the prosthetic field, the surrounding hard dental and soft tissues, is one of the main and most important stages in the process of making any fixed prosthetic construction [1].

From its beginning around 7000 BC. until now, the development of dental medicine has invariably been associated with remarkable inventions, innovations and achievements. Over the last three decades, CAD / CAM (computer-aided design and computer-aided manufacturing) technology has entered rapidly and gained great popularity, providing better working conditions and increasing the comfort of both doctors and their patients. The purpose of the creation and introduction of CAD / CAM technology is to solve three main challenges in dentistry - to ensure sufficient durability of restorations, especially in the distal area, to create restorations with a more natural appearance and to facilitate and shorten the process of making these restorations, which would also increase their accuracy [2].

From a clinical point of view, two of the main criteria for achieving long-term success in prosthetic treatment with fixed prosthetic constructions are good marginal adaptation and accurate fit to the prepared hard dental tissues [3, 4, 5]. Their achievement depends on the exact and precise implementation of each clinical and laboratory stage: from the impression, through the working model, to the design and manufacture of prosthetic restoration [6]. In modern prosthetic dentistry, impressions taken using polyether and vinyl polysiloxane impression materials are common and a routine for most dentists. These impression materials have undergone such development and improvement that it is difficult to reproach their qualities and properties in case of imperfections and inaccuracies obtained in the prosthetic restorations. There is much evidence in the available literature to confirm their stability and accuracy $[7,8]$.

The development of intraoral scanners aims to overcome some limitations of conventional methods, such as volumetric changes in impression materials, the expansion of plaster in the casting of working models, as well as errors that may be made during production technology in the manufacture of prosthetic restorations [9]. Other factors that can affect the accuracy of conventional impressions are: incorrect choice of impression tray, poor soft tissue retraction, deformation of the impression during its removal from the patient's mouth and improper casting of the working model [10]. 
Digital impressions eliminate some of the stages in conventional impression techniques (CIT), such as tray selection, adhesive application, disinfection, transportation to the dental laboratory. This saves clinical time and reduces patient discomfort when taking a conventional impression.

Data on similar accuracy in partial dental arch scanning and conventional impressions have been found in the available literature [11]. However, in their in vivo study by Ender et al. from 2016 reports that digital impressions of a whole dental arch show less accuracy compared to conventional techniques, especially in the area of the molars [8]. According to Goracci et al., there is a lack of up-to-date clinical evidence when scanning an entire dental arch [12]. That is why Ahlholm et al. recommend conventional impression techniques with elastomeric impression materials in prosthetic treatment with large fixed structures [13].

Despite the many benefits of intraoral scanning systems, a small number of dentists have introduced them into their practices. This is mainly due to the high initial investment for the purchase of an intraoral scanner and software, the costs associated with its maintenance and the time and effort required to improve work with it. In the long run, frequent use of the system is necessary to recoup the investment [1].

\section{AIM:}

The purpose of this article is to compare the clinical time of digital and conventional impression techniques from a whole dental arch using a controlled clinical trial.

\section{MATERIALS AND METHODS:}

The study was conducted as a controlled clinical trial, which compared the time required to perform conventional and digital impression techniques (DIT). All participants were informed in detail about the possible risks and benefits of this study and signed an informed consent form for participation in the research. The research protocol was approved by the Commission for Scientific Research Ethics at the Medical University, Varna.

The present study included 36 patients from Varna who need prosthetic treatment with a fixed 3-unit fixed partial denture. All subjects meet the following criteria:

- be over 18 years of age,

- have distally limited dental defects,

- have signed an informed consent form,

- have good or satisfactory oral hygiene,

- have high aesthetic requirements,

- need treatment with three-unit bridge constructions,

- patients in whom the abutment teeth do not require long-term pre-prosthetic preparation (e.g. teeth with periapical lesions),

- patients in whom the adjacent teeth, as well as the antagonists in the prosthetic restoration area, are present and healthy or adequately restored.

For all participants in the clinical trial, the con- ventional impression technique was performed first and one week later, the digital one. All clinical manipulations related to the implementation of the two impression techniques were performed according to the instructions of the manufacturers by a dentist with an acquired speciality in Prosthetic Dentistry, who has extensive experience in the field of fixed prosthetics and working with conventional impression materials. He underwent special training using an intraoral scanner lasting more than 20 hours in order to master the technique of working with it.

The abutment teeth were prepared with a shoulder preparation margin with rounded internal angles under constant water cooling according to the preparation recommendations for full coverage crowns made from zirconium dioxide [14]. The approximate width of the preparation margin was between 0,5 and $0,8 \mathrm{~mm}$, the axial reduction $-1,0-1,2 \mathrm{~mm}$, occlusal reduction $-1,5$ $\mathrm{mm}$ and total axial wall convergence of 6-8 ${ }^{\circ}$. After teeth preparation, interim fixed partial dentures made from poly(methyl methacrylate) (PMMA Disc, Yamahachi Dental, Japan) were placed over the abutments. The interim restorations were cemented with a eugenol-free temporary cement (DentoTempAutomix, Itena, France). For each patient, a conventional (control group) and digital (test group) impression technique was used, on which two fixed partial dentures from full contour zirconium dioxide were made.

Before performing each impression technique, the prosthetic field was prepared, which included removing the temporary restoration, cleaning the prepared hard dental tissues from the temporary cement and retracting the gingival sulcus using two retraction cords (Ultrapak, Ultradent Products Inc.., USA) and an impregnating agent from the group of $\alpha$-adrenomimetic decongestants (Xylometazoline 0.05\%, Warsaw Pharmaceutical Works Polfa SA, Poland) in order to clearly visualize the preparation margin [15]. One conventional and one digital impression from the upper and lower jaw was taken from each patient.

We used an intraoral scanner (Trios, 3Shape, Denmark) to perform the digital impression technique. Scanning of both jaws and an occlusal register in a state of central occlusion was performed in the sequence recommended by the manufacturer, namely: starting from the occlusal-palatal surface of the last molar in the first quadrant, moving to the opposite side of the jaw, always including two surfaces and return to the first quadrant of the vestibular. We repeated the same sequence for the lower jaw, starting from the third or fourth quadrant.

The conventional approach uses a two-stage twolayer impression technique with additive silicone impression material (Variotime 2 putty and light body, Kulzer, GmbH, Germany) and standard metal trays (Medesy, Impression trays, Italy). We used an irreversible hydrocolloid (Tropicalgin, Zhermack, Dental Products, Italy) to take an impression of the antagonist teeth. The occlusal record was taken in a state of centric occlusion using special PVS material (Varitotime bite, 


\section{Kulzer GmbH, Germany).}

The quality of the conventional and digital impressions was assessed, and if they did not meet the requirements, they were repeated from the beginning (for conventional impressions), or an additional scan of the affected area was made (for digital impressions). All conventional impressions were disinfected with $2 \%$ solution for 5 minutes (Zeta 7 Solution, Zhermack, Italy). Both types of impressions were sent to the dental laboratory by conventional means or via the Internet.

We evaluated the effectiveness and clinical results of the conventional impression technique by measuring the total clinical time. The measurement started from the moment of selection of the impression tray and ended when the taken impression was ready for transmission to the dental laboratory (Figure 1).

Fig. 1. Conventional impression technique. A) Adhesive application; B) Placement of the light body material; C) Taking impression from the upper jaw; D) Impression from the upper jaw, lower jaw and occlusal bite registration.

A
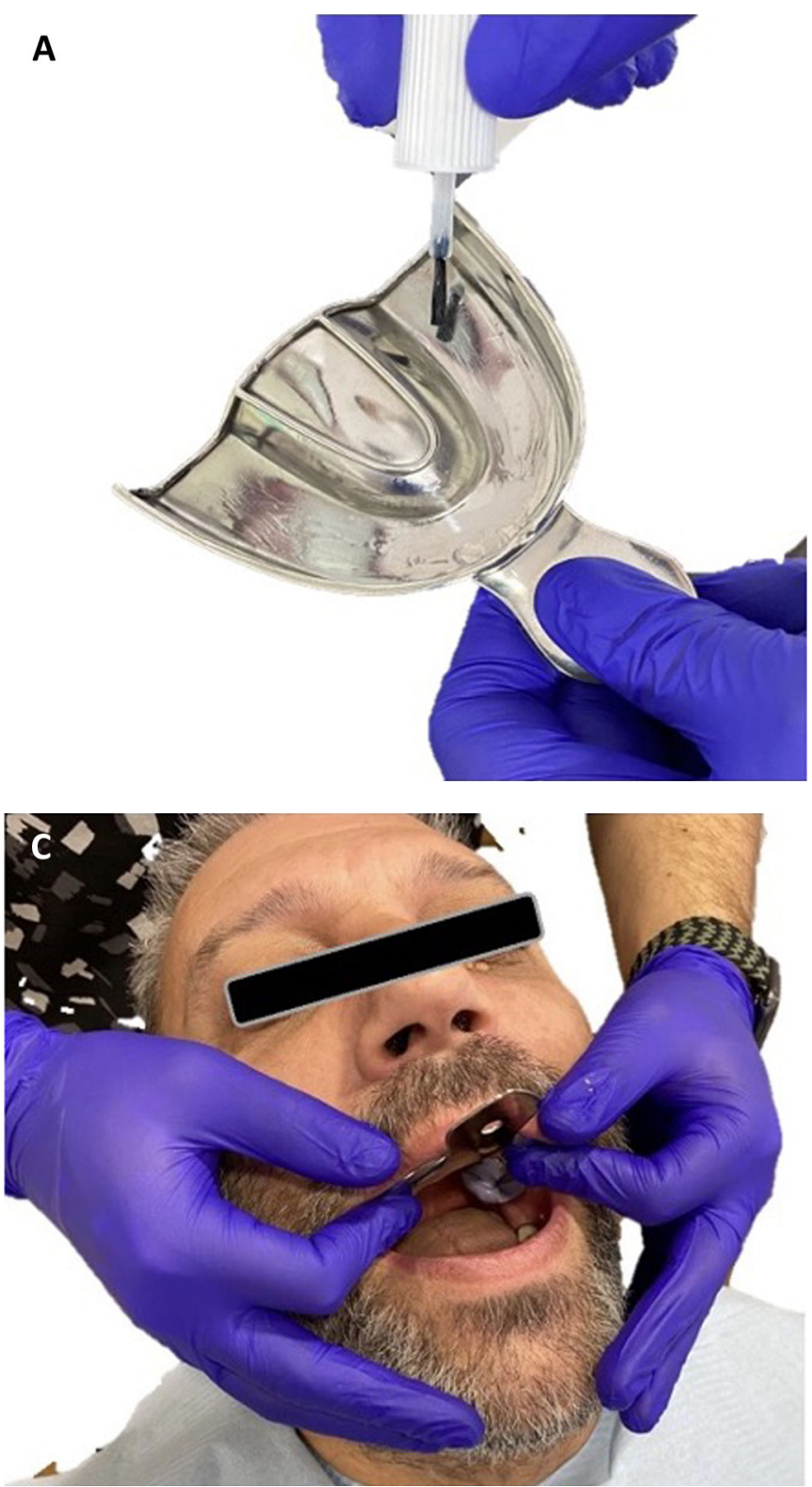

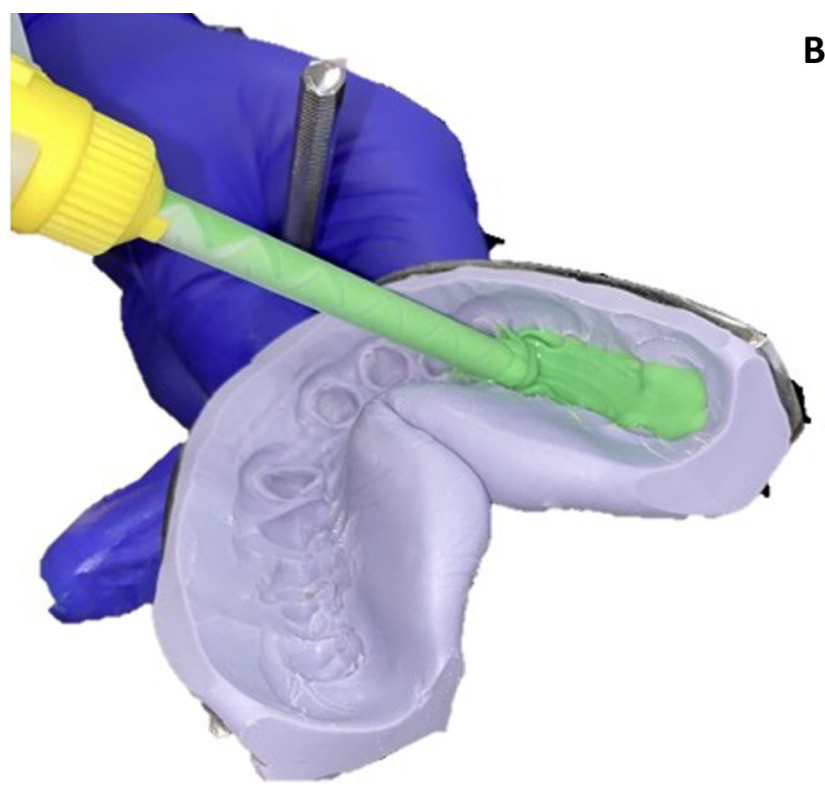

B

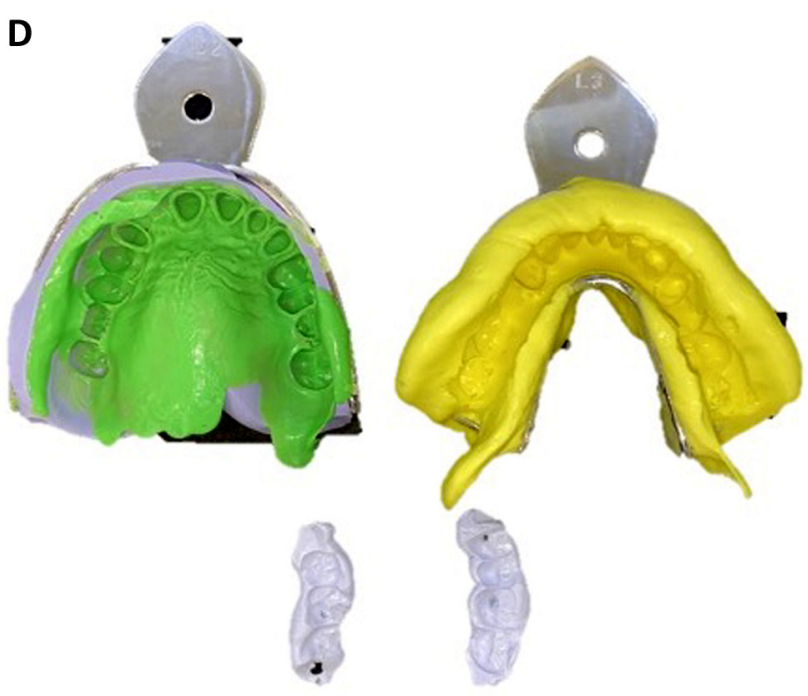

We evaluated the effectiveness and clinical results of the digital impression technique by measuring the total clinical time. The measurement started from the moment the device was turned on until the moment of final processing of the digital information and it's switching off (Figure 2). 
Fig. 2. Digital impression technique. A) Entering patient and laboratory information B) Lower and upper jaw scanning; C) Occlusal bite registration; D) Digital impression.
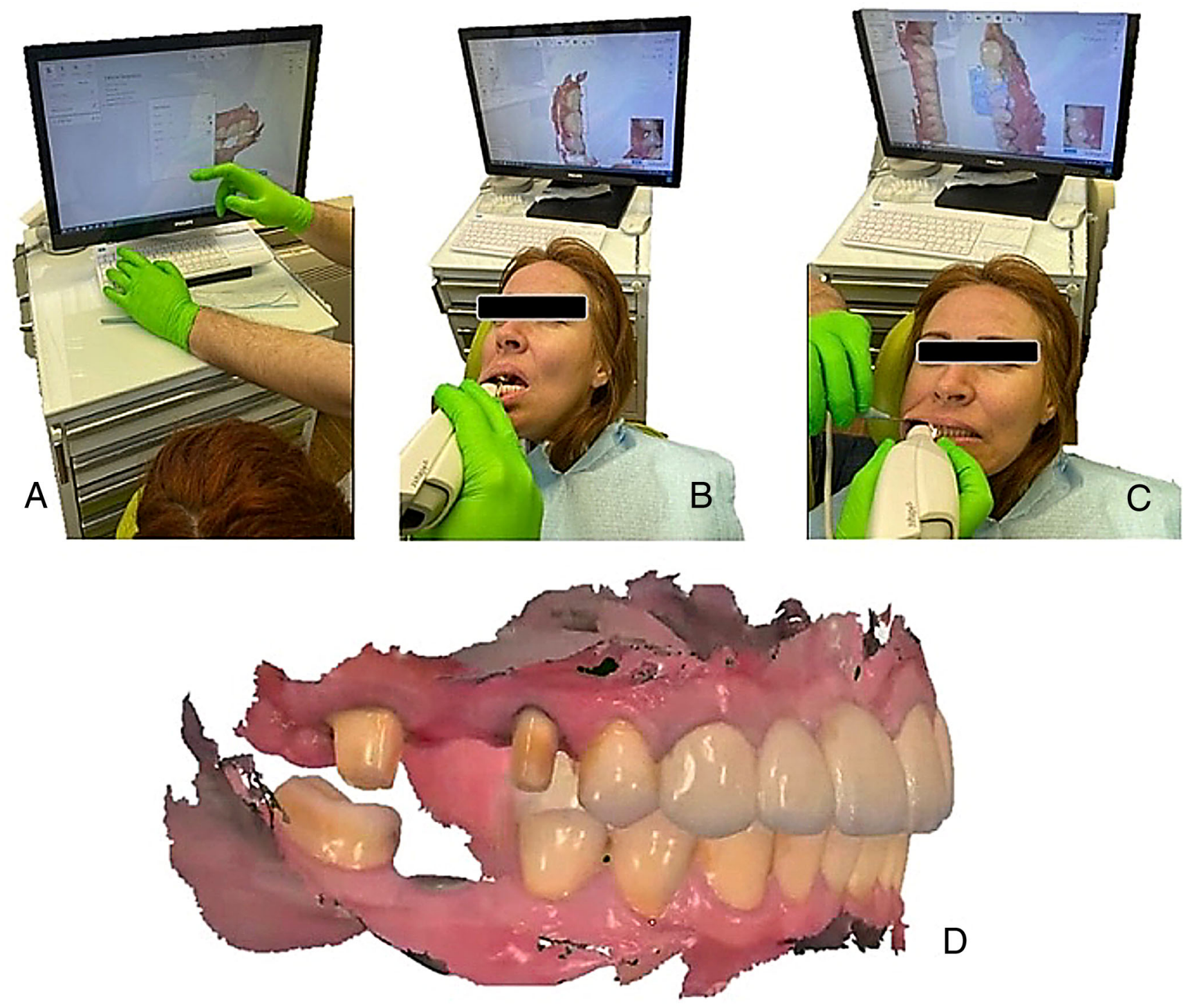

The times were measured in minutes and seconds with the help of a smartphone chronometer (IPhone11 pro max, Apple, USA) and recorded for each intermediate stage by a second operator in specially developed tables.

The obtained data was entered and processed with the mathematical-statistical package SPSS (SPSS Statistics v.20.0; IBM Corp).

\section{RESULTS:}

The clinical study included 13 women and 23 men with an average age of 48.3 years $\pm 6,89$ years (minimum age 31 years, maximum 59 years). A total of 72 teeth were prepared, of which 31 were molars (13 on the upper jaw and 18 on the lower jaw), 26 - premolars (13 on the upper jaw and 13 on the lower jaw), 10 - canine teeth ( 9 on the upper jaw and 1 on the lower jaw) and 5 - incisors. The total number of bridge bodies is 36 , of which 20 are molars ( 8 on the upper jaw and 12 on the lower jaw), 11 are premolars ( 7 on the upper jaw and 4 on the lower jaw), and 5 are incisors.
The evaluation of the clinical time for both impression techniques is shown in Table 1 . In all participants, the total time required to perform the digital impression technique is significantly less than that of the conventional impression technique. The mean total clinical time \pm SD (standard deviation) is 33:51 min. \pm 1:05 min. for conventional impression technique and 16:03 min. \pm 0:43 min. for digital impression technique with Trios, 3Shape (Table 1 and Table 2). The differences between CIT and DIT ( $\mathrm{p}<$ $0.05)$ show a statistically significant difference.

The two-stage two-layer impression technique from the prosthetic field had to be repeated for six patients and in four others - from the antagonist teeth due to inaccuracies in the impressions taken. Digital impression correction was performed in 7 patients, and the occlusal bite was rescanned in four others.

The mean clinical times of the different stages of the conventional impression techniques was: Mean impression tray selection and adhesive application time was 3:08 \pm 0:14 min; mean impression time from the abutment teeth 
was 17:41 \pm 0:43 min; mean impression time from the antagonists was 3:19 \pm 0:15 min; mean bite registration time was 1:39 \pm 0:09 min; mean evaluation and disinfection time 6:36 $\pm 0: 10 \mathrm{~min}$ and mean shade selection time was $1: 25 \pm 0: 14$.

The mean clinical times of the different stages of the digital impression techniques was: Meantime for switching the scanner on and entering patient information was 2:04 \pm 0:17 min; meantime for entering laboratory information was $1: 36 \pm 0: 13$; mean time for scanning the upper jaw was 3:36 $\pm 0: 38$ min; mean time for scanning the lower jaw was $4: 37 \pm 0: 37$; mean bite registration time was 0:55 $\pm 0: 20 \mathrm{~min}$; and mean evaluation and post processing time was $2: 34 \pm 0: 31 \mathrm{~min}$.
Based on the measurements done, we found that the mean total time for scanning the lower jaw was longer $(4: 37$ min. $\pm 0: 37 \mathrm{~min}$.) compared to the time required to scan the upper jaw (3:36 min. \pm 0:38 min.). Comparing the same indicator with the conventional impression technique, no statistically significant difference $(\mathrm{p}>0.05$.) was found in the time required for taking an impression from the upper and lower jaw - 17:42 min \pm 0:43 min mean time for upper jaw and 17:41 min. $\pm 0: 37$ min. mean time for the lower jaw. The mean time for the implementation of the conventional impression technique for men is 33:52 min. \pm 1:05 min., and for women $-33: 49 \mathrm{~min} . \pm$ 0:57 min., while for the digital impression technique, it is: 16:02 $\mathrm{min} \pm 0: 44$ min. in men and 16:01 $\min \pm 0: 39 \mathrm{~min}$. in women.

Table 1. Mean clinical and total time of the digital impression technique.

\begin{tabular}{lcccc}
\hline & Digital impression technique & & & \\
\hline Studied indicator & Mean & $\begin{array}{c}\text { Standard } \\
\text { deviation }\end{array}$ & $\begin{array}{c}\text { Minimum } \\
\text { value }\end{array}$ & $\begin{array}{c}\text { Maximum } \\
\text { value }\end{array}$ \\
\hline 1. Switching the scanner on and entering patient in formation & $02: 04$ & $\pm 0: 17$ & $01: 41$ & $03: 10$ \\
\hline 2. Entering laboratory in formation & $01: 36$ & $\pm 0: 13$ & $01: 06$ & $02: 28$ \\
\hline 3. Upperjawscan & $03: 36$ & $\pm 0: 38$ & $02: 05$ & $05: 14$ \\
\hline 4. Lower jaw scan & $04: 37$ & $\pm 0: 37$ & $03: 20$ & $05: 28$ \\
\hline 5. Occlusal bite registration & $01: 35$ & $\pm 0: 10$ & $01: 07$ & $02: 02$ \\
\hline 6. Evaluationandpostprocessing & $02: 34$ & $\pm 0: 31$ & $01: 53$ & $04: 58$ \\
\hline TOTAL TIME & $16: 03$ & $\pm 0: 43$ & $13: 57$ & $17: 48$
\end{tabular}

Table 2. Mean clinical and total time of the conventional impression technique.

\begin{tabular}{lcccc}
\hline \multicolumn{2}{c}{ Conventional impression technique } & & & \\
\hline Studied indicator & Mean & $\begin{array}{c}\text { Standard } \\
\text { deviation }\end{array}$ & $\begin{array}{c}\text { Minimum } \\
\text { value }\end{array}$ & $\begin{array}{c}\text { Maximum } \\
\text { value }\end{array}$ \\
\hline 1. Impression tray selection and adhesive application & $03: 08$ & $\pm 0: 14$ & $02: 26$ & $03: 34$ \\
\hline 2. Impression from the abutment teeth & $17: 41$ & $\pm 0: 43$ & $15: 29$ & $19: 57$ \\
\hline 3. Impression from the antagonists & $03: 19$ & $\pm 0: 15$ & $02: 50$ & $03: 54$ \\
\hline 4.Occlusal bite registration & $01: 39$ & $\pm 0: 09$ & $01: 27$ & $02: 06$ \\
\hline 5. Evaluation and disinfection & $06: 36$ & $\pm 0: 10$ & $06: 18$ & $07: 00$ \\
\hline 6. Shadeselection & $01: 25$ & $\pm 0: 14$ & $00: 51$ & $01: 50$ \\
\hline TOTAL TIME & $33: 51: 00$ & $\pm 1: 05$ & $30: 59: 00$ & $36: 45: 00$
\end{tabular}

\section{DISCUSSION:}

Based on the analysis of the mean times at all intermediate stages in both types of impression technique, we came to the conclusion that some of them do not have a significant impact on the overall clinical time. In the conventional impression technique, these are: the stage of selection of trays and application of adhesive, evaluation of the finished impressions and their disinfection and the time for determining the color of the bridge structure. In digital impression technology, these are: the stage of turning on the device and entering information about the patient, entering information about the laboratory and the final processing of the digital file. The difference in the mean times of the two techniques is determined mainly by the stages of taking conventional and digital impressions from the two dentitions, as well as the occlusal registers.

During the implementation of the conventional impression technique, the recommended times by the manufacturer for processing and residence of the impression materials in the patient's mouth in order to complete the polymerization process were kept. Reducing these times would lead to a shorter overall clinical time when performing the conventional technique, which would negatively affect the quality and accuracy of the impression [16]. In modern prosthetic dentistry, two types of impression techniques are mostly used to take a conventional impression 
from the prosthetic field: one-stage two-layer and two-stage two-layer. In the present study, we used a two-stage twolayer additive with silicone additive (Variotime 2 putty and light body, Kulzer, GmbH, Germany), which takes significantly more time to perform compared to the single-stage two-layer technique. The choice of which of the two techniques to use was made mainly due to the greater volumetric stability and accuracy of the two-layer technique. This statement is supported by studies by Chee and Donovan and Nissan et al., according to which one-step methods show less accuracy than two-step [17,18]. The main disadvantage of the conventional approach is the need to repeat the impression from the beginning when visible defects are found in it. This would adversely affect the overall clinical time. A great advantage of the digital impression technique is evaluating the digital impression in real time and correcting a certain part of it by re-scanning without having to start over.

Several clinical trials have been found in the available literature that analyze the time required to perform digital and conventional impression techniques. The results of these studies are mixed [19-22]. Here it should be clarified that there is a dependence on the assessment method used and the type of the impression itself: whether it is a whole or a partial dental arch.

Similar results were obtained by Haddadi et al., according to which the time required to take a digital impression from a whole dental arch is less compared to a conventional impression with PVS [23]. Another study proving shortened clinical time using an intraoral scanning system was conducted by Joda and Bragger. They reported significantly shorter clinical time for digital impressions than conventional ones (27.3 minutes vs 33.2 minutes). As a dis- advantage of this study, it can be noted that the authors compare digital impressions of a partial dental arch with conventional impressions of a whole dental arch [24]. Shortened clinical time and increased patient comfort when taking a digital impression were also reported by Yuzbasioglu et al. in their 2014 study [22]. On the other hand, Sailer et al. reported that the clinical time required to take an impression of a whole dental arch is less with the conventional impression technique compared to the digital one. However, in their study, the authors use a single-stage two-layer impression technique, which requires much less implementation time [21]. In their study, Grünheid et al. obtain similar results, a namely faster clinical time when taking impressions of whole dental arches with the conventional impression technique. However, in this study, the conventional whole arch impression technique was performed with an irreversible hydrocolloid, which took significantly less time than the use of an elastomeric impression material [20].

\section{CONCLUSION:}

Within the limitations of the current controlled clinical trial, the following conclusions can be drawn:

1. The digital impression technique has proven to be more efficient in terms of clinical time required for its implementation than the conventional impression technique.

2. If the conventional impression does not meet the necessary requirements, it must be repeated from the beginning, which increases the clinical time.

3. With digital impressions, it is possible to correct a certain area of it without having to start over. This leads to a shorter clinical time.

\section{REFERENCES:}

1. Christensen GJ. The challenge to conventional impressions. J Am Dent Assoc. 2008 Mar;139(3):347-9. [PubMed]

2. Davidowitz G, Kotick PG. The use of CAD/CAM in dentistry. Dent Clin North Am. 2011 Jul;55(3):559-70. [PubMed]

3. Abdel-Azim T, Rogers K, Elathamna E, Zandinejad A, Metz M, Morton D. Comparison of the marginal fit of lithium disilicate crowns fabricated with CAD/CAM technology by using conventional impressions and two intraoral digital scanners. $J$ Prosthet Dent. 2015 Oct;114(4):554-9. [PubMed]

4. Almeida e Silva JS, Erdelt K, Edelhoff D, Araujo E, Stimmelmayr M, Vieira LC, et al. Marginal and internal fit of four-unit zirconia fixed dental prostheses based on digital and con- ventional impression techniques. Clin Oral Investig. 2014; 18(2):515-23. [PubMed]

5. Papadiochou S, Pissiotis AL. Marginal adaptation and CAD-CAM technology: a systematic review of restorative material and fabrication techniques. J Prosthet Dent. 2018 Apr; 119(4):545-551. [PubMed]

6. Schonberger J, Erdelt KJ, Baumer D, Beuer F. Marginal and internal ût of posterior three-unit ûxed zirconia dental prostheses fabricated with two different CAD/CAM systems and materials. Clin Oral Investig. 2017 Nov; 21(8):2629-35. [PubMed]

7. Shetty P, Rodrigues S. Accuracy of elastomeric impression materials on repeated pours. J Indian Prosthodont Soc. 2006; 6(2):68-71.

8. Ender A, Attin T, Mehl A. In vivo precision of conventional and digital methods of obtaining complete-arch dental impressions. J Prosthet Dent. 2016 Mar;115(3):313-20. [PubMed]

9. Miyazaki T, Hotta Y, Kunii J, Kuriyama S, Tamaki Y. A review of dental CAD/CAM: current status and future perspectives from 20 years of experience. Dent Mater J. 2009 Jan; 28(1):44-56 [PubMed]

10. Christensen GJ. The state of fixed prosthodontic impressions: room for improvement. J Am Dent Assoc. 2005 Mar;136(3):343-346. [PubMed]

11. Ender A, Zimmermann M, Attin $\mathrm{T}$, Mehl A. In vivo precision of conventional and digital methods for obtaining quadrant dental impressions. Clin Oral Investig. 2016 Sep;20(7): 1495-504. [PubMed]

12. Goracci C, Franchi L, Vichi A, Ferrari M. Accuracy, reliability, and eficiency of intraoral scanners for full- 
arch impressions: A systematic review of the clinical evidence. Eur J Orthod. 2016 Aug;38(4):422-8. [PubMed]

13. Ahlholm P, Sipila K, Vallittu P, Jakonen M, Kotiranta U. Digital versus conventional impressions in fixed prosthodontics: Areview. J Prosthodont. 2018 Jan;27(1):35-41. [PubMed]

14. Podhorsky A, Rehmann P, Wostmann B. Tooth preparation for full-coverage restorations-a literature review. Clin Oral Investig. 2015 Jun; 19(5):959-968. [PubMed]

15. Katreva Iv. [Advantages of $\alpha$ adrenomimetic Decongestants over Conventional Chemical Agents for Gingival Retraction in Order to Avoid Adverse Systemic Side Effects.] [Dissertation] Medical University Varna, Bulgaria. 2015. 140 p [in Bulgarian]

16. Balkenhol M, Kanehira M, Finger WJ, Wöstmann B. Working time of elastomeric impression materials: relevance of rheological tests. Am J Dent, 2007 Dec;20(6):347-352. [PubMed]

17. Chee WWL, Donovan TE. Polyvinyl siloxane impression materials: a review of properties and techniques. $J$ Prosthet Dent. 1992 Nov;68(5):728732. [PubMed]

18. Nissan J, Laufer BZ, Brosh T, AssifD.Accuracy of three polyvinyl siloxane putty-wash impression techniques. J Prosthet Dent. 2000 Feb; 83(2):161-165. [PubMed]

19. Benic GI, Muhlemann S, Fehmer V, Hammerle CH, Sailer I. Randomized controlled within-subject evaluation of digital and conventional workflows for the fabrication of lithium disilicate single crowns. Part I: digital versus conventional unilateral impressions. J Prosthet Dent. 2016 Nov;116(5):777-82. [PubMed]

20. Grunheid T, McCarthy SD, Larson BE. Clinical use of a direct chairside oral scanner: an assessment of accuracy, time, and patient acceptance. Am J Orthod Dentofacial Orthop. 2014 Nov;146(5):673-82. [PubMed]

21. Sailer I, Muhlemann S, Fehmer V, Hammerle CHF, Benic GI. Randomized controlled clinical trial of digital and conventional workflows for the fabrica- tion of zirconia-ceramic fixed partial dentures. Part I: Time efficiency of complete-arch digital scans versus conventional impressions. J Prosthet Dent. 2019 Jan;121(1):69-75. [PubMed]

22. Yuzbasioglu E, Kurt H, Turunc $\mathrm{R}$, BilirH.Comparison of digital and conventional impression techniques: evaluation of patients' perception, treatment comfort, effectiveness and clinical outcomes. BMC Oral Health. 2014 Jan;30:14:10. [PubMed]

23. Haddadi Y, Bahrami G, Isidor F. Evaluation of Operating Time and $\mathrm{Pa}-$ tient Perception Using Conventional Impression Taking and Intraoral Scanning for Crown Manufacture: A Splitmouth, Randomized Clinical Study. Int J Prosthodont. 2018 Jan-Feb;31(31): 55-59. [PubMed]

24. Joda T, Bràgger U. Time-Efficiency Analysis Comparing Digital and Conventional Workflows for Implant Crowns: A Prospective Clinical Crossover Trial. Int J Oral Maxillofac Implants. 2015 Sep-Oct;30(5):1047-53. [PubMed]

Please cite this article as: Gogushev K, Abadjiev M. Conventional vs Digital Impression Technique for Manufacturing of Three-unit Zirconia Bridges: Clinical Time Efficiency. J of IMAB. 2021 Apr-Jun;27(2):3765-3771.

DOI: https://doi.org/10.5272/jimab.2021272.3765

Received: 25/02/2021; Published online: 04/06/2021

Address for correspondence:

Kiril Gogushev,

Department of Clinics of prosthetic dentistry, Faculty of Dental medicine, Medical University - Varna.

84, Tsar Osvoboditel Blvd., 9000 Varna, Bulgaria

E-mail: kiril.gogushev@gmail.com 